\title{
The Burden of HIV/AIDS in Ethiopia from 1990 to 2016: Evidence from the Global Burden of Diseases 2016 Study
}

Amare Deribew ${ }^{12^{*}}$, Sibhatu Biadgilign ${ }^{3}$, Kebede Deribe ${ }^{4,5}$, Tariku Dejene ${ }^{6}$, Gizachew Assefa Tessema ${ }^{7,8}$, Yohannes Adama Melaku ${ }^{9,10}$, Yihune Lakew ${ }^{11}$, Azmeraw T.Amare ${ }^{12,13}$, Tolessa Bekele ${ }^{14}$, Semaw F. Abera ${ }^{9,15,16}$, Muluken Dessalegn $^{17}$, Andargachew Kumsa ${ }^{18}$, Yibeltal Assefa ${ }^{19}$, Scott D Glenn ${ }^{20}$, Tahvi Frank $^{20}$, Austin Carter ${ }^{20}$, Awoke Misganaw ${ }^{20}$, Haidong Wang ${ }^{20}$

\section{OPEN ACCESS}

Citation: Amare Deribew, Sibhatu Biadgilign, Kebede Deribe, Tariku Dejene, Gizachew Assefa Tessema,Yohannes Adama Melaku, Yihune Lakew, Azmeraw T.Amare, Tolessa Bekele, Semaw F. Abera, Muluken Dessalegn, Andargachew Kumsa, Yibeltal Assefa, Scott D Glenn, Tahvi Frank, Austin Carter, Awoke Misganaw, Haidong Wang. The Burden of HIV/AIDS in Ethiopia from 1990 to 2016: Evidence from the Global Burden of Diseases 2016 Study. Ethiop J Health Sci. 2018;29(1):859.

doi:http://dx.doi.org/10.4314/ ejhs.v29i1.7 Received: July 16, 2018

Accepted: July 23, 2018

Published: January 1, 2019

Copyright: (C) 2018 Amare Deribew, et al. This is an open access article distributed under the terms of the Creative Commons Attribution License, which permits unrestricted use, distribution, and reproduction in any medium, provided the original author and source are credited. Funding: Nil.

Competing Interests: The authors declare that this manuscript was approved by all authors in its form and that no competing interest exists.

Affiliation and Correspondence:

${ }^{1}$ St. Paul Millennium Medical College, Addis Ababa, Ethiopia

Hospital

${ }^{2}$ Nutrition International, Ethiopia

${ }^{3}$ World Health Organization, Uganda

${ }^{4}$ Wellcome Trust Brighton \& Sussex

Centre for Global Health Research, Brighton \& Sussex Medical School, Falmer, Brighton, UK

${ }^{5}$ School of Medicine, Addis Ababa University, Ethiopia

${ }^{6}$ Center for Population Studies, Addis Ababa University, Addis Ababa, Ethiopia

${ }^{7}$ School of Public Health, University of Adelaide, Adelaide, Australia

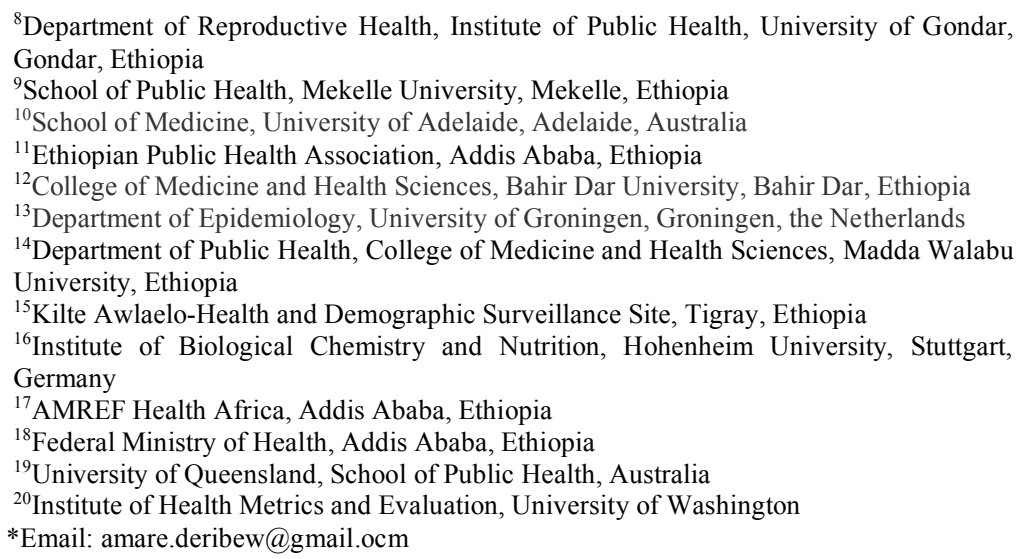

\section{ABSTRACT}

BACKGROUND: The burden of HIV/AIDS in Ethiopia has not been comprehensively assessed over the last two decades. In this study, we used the 2016 Global Burden of Diseases, Injuries and Risk factors (GBD) data to analyze the incidence, prevalence, mortality and Disability-adjusted Life Years Lost (DALY) rates of Human Immunodeficiency Virus / Acquired Immune Deficiency Syndrome (HIV/AIDS) in Ethiopia over the last 26 years.

METHODS: The GBD 2016 used a wide range of data source for Ethiopia such as verbal autopsy (VA), surveys, reports of the Federal Ministry of Health and the United Nations (UN) and published scientific articles. The modified United Nations Programme on HIV/AIDS (UNAIDS) Spectrum model was used to estimate the incidence and mortality rates for HIV/AIDS.

RESULTS: In 2016, an estimated 36,990 new HIV infections (95\% uncertainty interval [UI]: 8775-80262), 670,906 prevalent HIV cases (95\% UI: 568,268-798,970) and 19,999 HIV deaths (95\% UI: 16426-24412) occurred in Ethiopia. The HIV/AIDS incidence rate peaked in 1995 and declined by 6.3\% annually for both sexes with a total reduction of 77\% between 1990 and 2016. The annualized HIV/AIDS mortality rate reduction during 1990 to 2016 for both sexes was $0.4 \%$. 
CONCLUSIONS: Ethiopia has achieved the $50 \%$ reduction of the incidence rate of HIV/AIDS based on the Millennium Development Goals (MDGs) target. However, the decline in HIV/AIDS mortality rate has been comparatively slow. The country should strengthen the HIV/AIDS detection and treatment programs at community level to achieve its targets during the Sustainable Development Program (SDGs)-era. KEYWORDS: Burden, GBD, HIV/AIDS, Ethiopia

\section{INRODUCTION}

The global momentum of HIV/AIDS interventions has been intensified since the launch of the Millennium Development Goals (MDG) that aimed to reduce the incidence of HIV/AIDS by $50 \%$ by $2015(1,2)$. However, HIV/AIDS is still the major public health problem globally. In 2015, there were about 1.1 million HIV/AIDS deaths, 2.1 million new HIV infections and a total of 36.7 million people who had HIV in their blood. Sub-Saharan Africa is the most affected region, with 25.6 million people living with HIV in 2015 (3).

The burden of HIV/AIDS remains high in Ethiopia despite a considerable scaleup of comprehensive HIV/AIDS interventions during the MDG period. In 2016, there were about 718,500 people living with HIV/AIDS (4). The 2017 UNAID global AIDS report revealed that the number of new HIV infections in Ethiopia were higher in 2016 than in 2010 (5). The reemergence of HIV/AIDS in Ethiopia could be due to the low coverage of high impact interventions. For instance, the 59\% coverage of Highly Active Antiretroviral Treatment (HAART) in Ethiopia is below the regional average, and only $67 \%$ of Ethiopians know their HIV status (5).

Achievement of the HIV/AIDS related Sustainable Development Goals (SDGs) in Ethiopia requires concerted efforts of scaling up comprehensive HIV/AIDS interventions and a robust health management information system (HMIS) that helps to evaluate the burden of HIV/AIDS. Over the last two decades, the prevalence, incidence and number of AIDS deaths have been estimated in Ethiopia using the Antenatal Care (ANC) based sentinel surveillance system (6). In this study, we used the Global Burden of Diseases (GBD) 2016 data (7-10) to assess the burden (prevalence, incidence, mortality and Disability-adjusted Life Years Lost rates) of HIV/AIDS over the last 26 years. There are several reasons to use the GBD data: First, it employs rigorous methods to estimate rates including DALY as described in the methods section of this article; second, GBD uses a standardized methodology that is essential to compare the performance of Ethiopia with that of other countries in terms of achieving the HIV/AIDS related targets. The study provides reliable information on the achievement of HIVrelated targets of the MDG. It also helps decision makers to allocate resources based on the burden of HIV/AIDS. Lastly, the study will serve as a baseline indicator to track progresses during the SDG era.

\section{METHODS}

The Ethiopian population (approximately 100 million) is the second largest in Africa with diverse population mix and unique cultural heritages (11). The GBD 2016 data were used to analyze the incidence, prevalence and mortality rates of HIV/AIDS. The GBD 2016 utilizes comprehensive sources of data and rigorous analysis to estimate trends of cause-specific mortality rates and risk factors for 188 countries $(7,8,10,12)$.

Data sources: The study employed a mathematical modeling using the GBD data. The GBD 2016 used a wide range of HIV/AIDS data for Ethiopia (http://ghdx.healthdata.org/). The key sources of data for HIV/AIDS include verbal autopsy, Demographic and Health Surveys (DHS) and data reported by the Ministry of Health to UNAIDS via the Spectrum software $(12,13)$. In addition, cohort data from throughout subSaharan Africa was used to estimate input parameters to the Ethiopian HIV epidemic model. 
Analysis strategies: The GBD uses recoded versions of the Epidemic and Projection Package (EPP) and Spectrum model which allow for drawlevel linkage between HIV estimates and all-cause mortality estimates $(14,15)$. The GBD populations and vital rates are used as inputs to the population projections within EPP and Spectrum. HIV mortality and disease progression parameters estimates differ from UNAIDS due to different data sources and modelling strategies. Within Spectrum, GBD methods included a novel approach to allocating ART across CD4 count groups with coverage distributions estimated using data from systematic review and survey. Estimates of HIV-specific mortality from the life table process are averaged with mortality rates coming from the epidemic model and, in order to preserve prevalence estimates, new HIV infections are back-calculated to align with updated mortality (10). Causes of death by age groups, sex and year for other diseases were measured using CODEm. A detailed description of CODEm is reported elsewhere $(12,16-18)$. In summary, CODEm tests and selects the bestperforming model from a wide range of models such as mixed-effects linear models and spatiotemporal Gaussian process regression (STGPR) models in predicting mortality rates and cause fractions (12).

Quality assurance: The GBD 2016 analysis uses reliable data including DHS, published articles and ministry of health reports. Unpublished data from other sources were excluded.

Ethical approval: The study used secondary data from the GBD 2016. The GBD 2016 data are anonymous and available and can be accessed at the GBD website (http://vizhub.healthdata.org/gbd-compare/).

\section{RESULTS}

Incidence: In 2016, there were an estimated 36,990 new HIV infections for all ages and sexes (95\% UI: 8775-80,262) in Ethiopia. The agestandardised incidence rate declined from $178 / 100,000$ to $40 / 100,000$ between 1990 and 2016 with a total reduction of $77 \%$. HIV incidence rate peaked in 1995, declined steadily till 2005 and have become stable since 2005. The annualized rate of change (ARC) for the HIV incidence rate during 1990 and 2016 was $-6.3 \%$ (Figure 1).

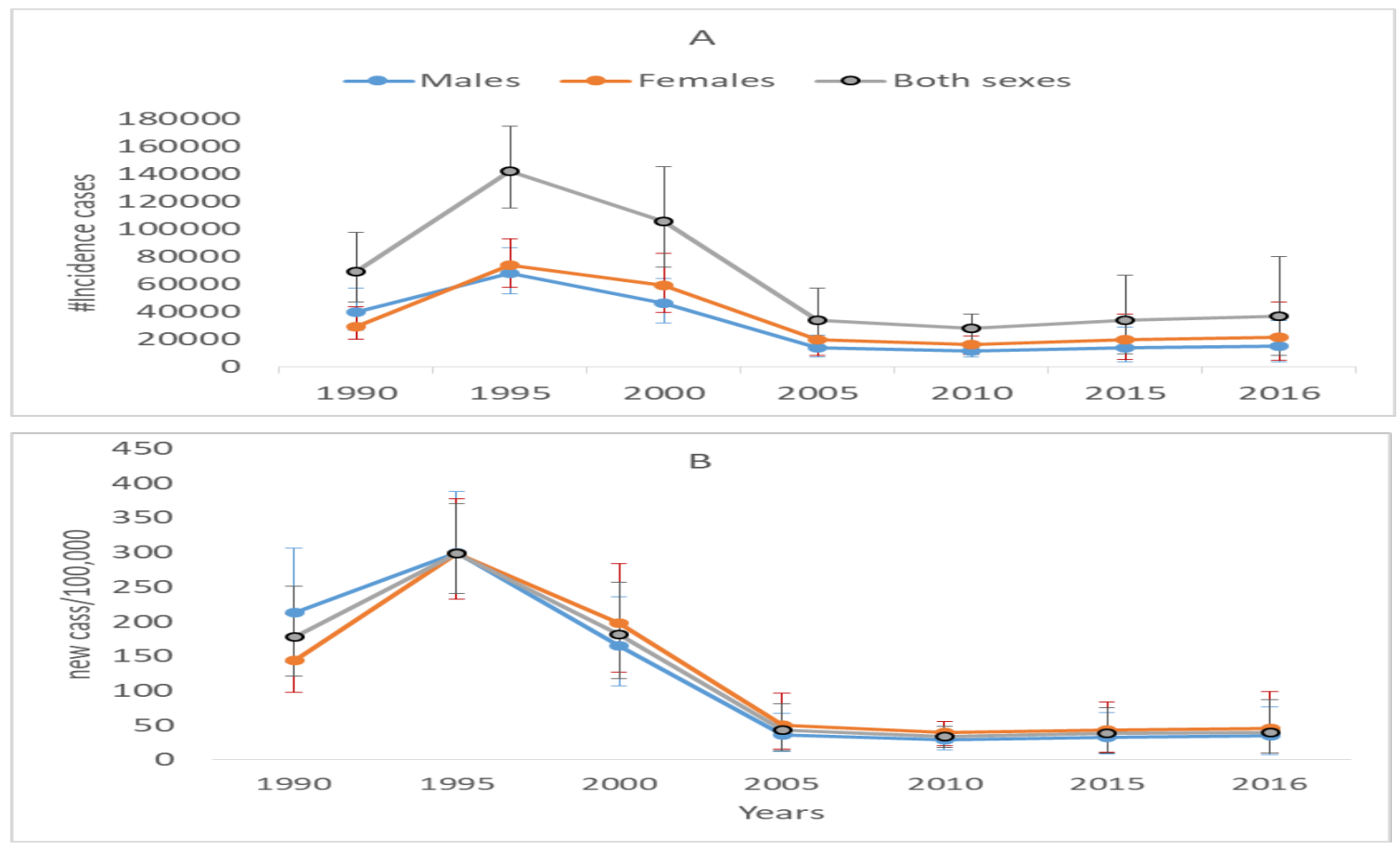

Figure 1: Number of New HIV infection (A) and HIV/AIDS incidence rate (B) by sex between 1990 and 2016.

DOI: http://dx.doi.org/10.4314/ejhs.v29i1.7 
Prevalence: An estimated 670,906 (95\% UI: 568, 268-798, 970) people living with HIV were registered in 2016. The number of females with HIV/AIDS $(385,642)$ was higher than the number of males $(285,263)$ with HIV/AIDS in 2016. The age-standardised HIV prevalence rate peaked in 2000 (1984 cases/100,000), declined steadily until 2010 and has remain stable thereafter (Figure 2).

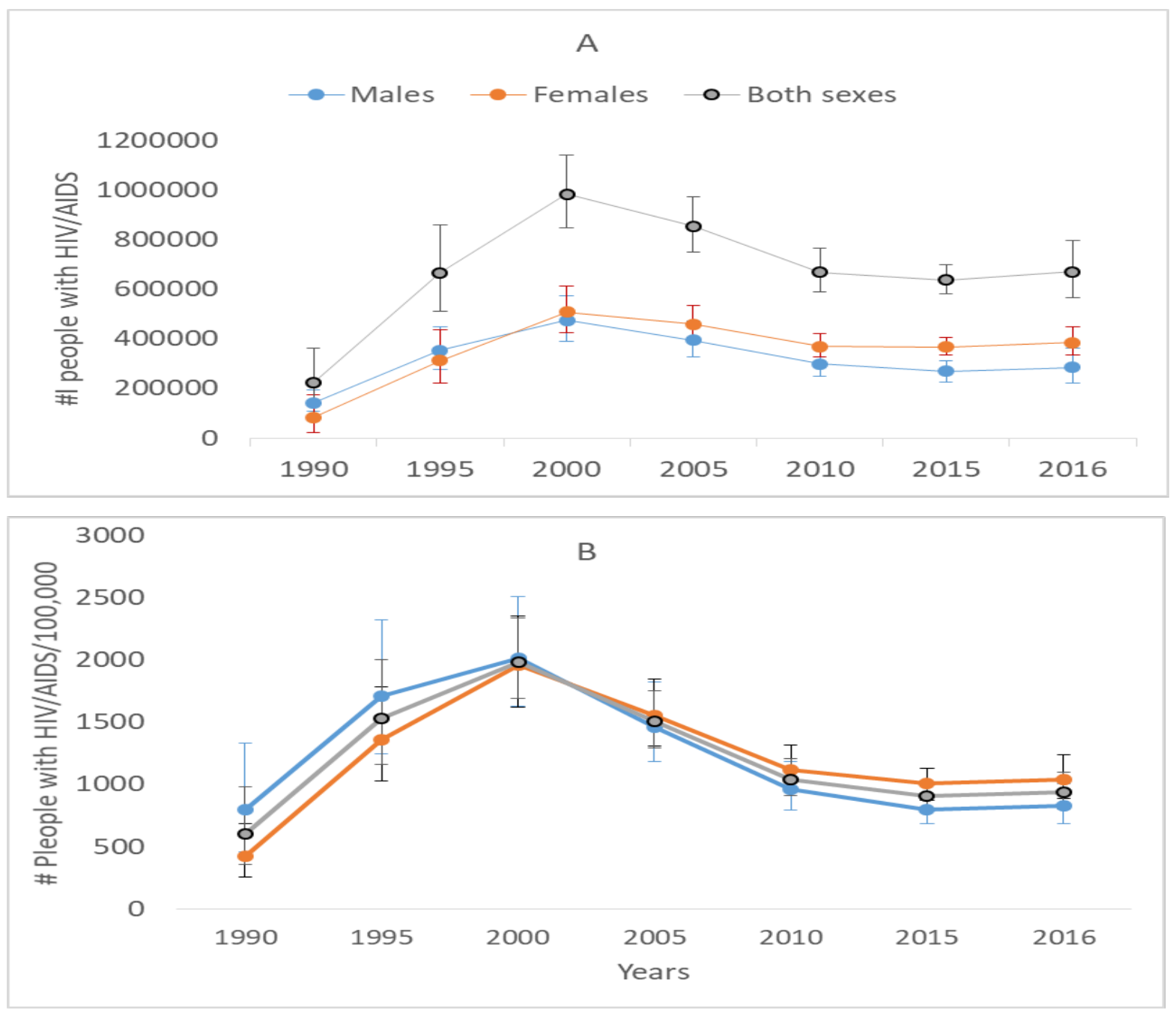

Figure 2: Number of people with HIV/Prevalence (A) and HIV/AIDS prevalence rate (B) by sex between 1990 and 2016

Mortality: In 2016, nearly 20,000 AIDS related deaths $(95 \%$ UI: $16,426-24,412)$ occurred in Ethiopia. AIDS mortality rate peaked in 2005 (150/100,000). The age-standardised AIDS mortality rate declined very fast after 2005 and reach 24/100,000 in 2016 (Table 1). In 2016, the number of HIV/AIDS deaths and mortality rate was highest in the age group of 35-54 years, and males and females had similar mortality patterns (Figure 3).

DOI: http://dx.doi.org/10.4314/ejhs.v29i1.7 
Table 1: Number of deaths and mortality rate of HIV/AIDS in Ethiopia, both sex between 1990 and 2016

\begin{tabular}{rrrrrrr}
\hline Year & \#Deaths & \multicolumn{2}{c}{$95 \%$ UI } & Rate/100,000 & \multicolumn{2}{c}{$95 \%$ UI } \\
\hline 1990 & 8010 & 4577 & 13757 & 22.6 & 12.7 & 39.3 \\
1995 & 33603 & 22959 & 47611 & 81.6 & 55.1 & 116.0 \\
2000 & 67311 & 49199 & 87753 & 145.8 & 106.4 & 188.1 \\
2005 & 78494 & 64146 & 93937 & 149.8 & 125.0 & 175.1 \\
2010 & 42288 & 36169 & 49483 & 64.3 & 54.5 & 75.6 \\
2015 & 21785 & 17628 & 26552 & 27.2 & 21.9 & 34.3 \\
2016 & 19999 & 16426 & 24412 & 24.2 & 19.8 & 29.8 \\
\hline
\end{tabular}

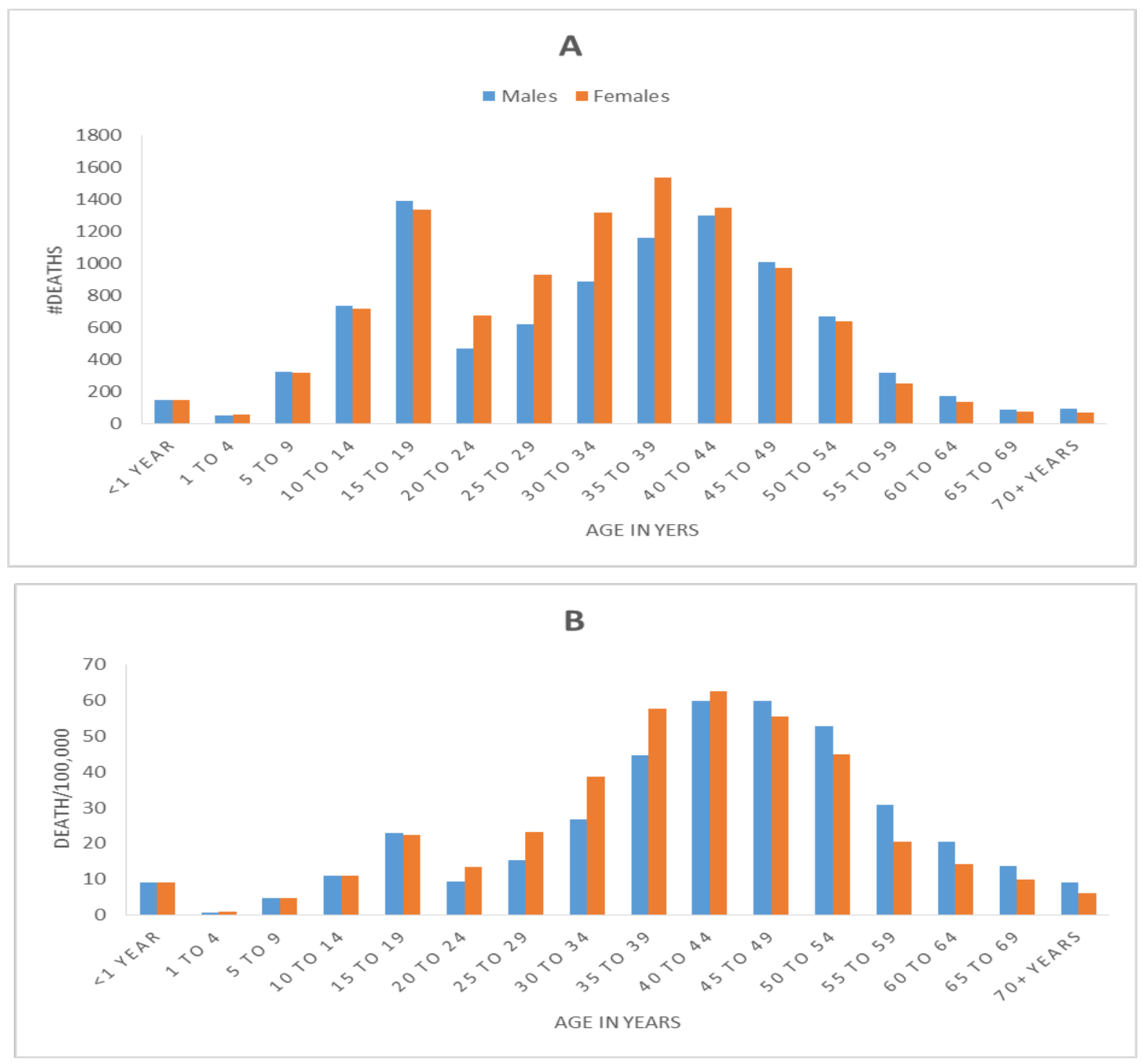

Figure 3: Number of HIVIAIDS deaths (A) and HIVIAIDS mortality rate (B) by age and sex in Ethiopia in 2016

DOI: http://dx.doi.org/10.4314/ejhs.v29i1.7 
DALY: An estimated 1.1 million (95\% UI: 0.9 million-1.4 million) AIDS related DALY were registered in Ethiopia in 2016. Age-standardised
AIDS DALY rate progressively increased between 1990 and 2005 and declined steadily since 2005 (Table 2).

Table 2: Number of DALY and DALY rate of HIV/AIDS in Ethiopia, both sex between 1990 and 2016.

\begin{tabular}{|c|c|c|c|c|c|c|}
\hline \multirow{2}{*}{$\begin{array}{l}\text { Year } \\
1990\end{array}$} & \multirow{2}{*}{$\begin{array}{l}\text { \#DALY } \\
443468\end{array}$} & \multicolumn{2}{|c|}{$95 \%$ UI } & $\begin{array}{l}\text { DALY } \\
\text { Rate/100,000 }\end{array}$ & \multicolumn{2}{|c|}{$95 \% \mathrm{UI}$} \\
\hline & & 271301 & 739129 & 1119.9 & 671.2 & 1889.4 \\
\hline 1995 & 1830619 & 1292847 & 2565490 & 3952.3 & 2729.0 & 5542.1 \\
\hline 2000 & 3621372 & 2708814 & 4697687 & 6958.2 & 5130.4 & 9007.0 \\
\hline 2005 & 4166924 & 3359603 & 5019628 & 7055.9 & 5726.2 & 8407.5 \\
\hline 2010 & 2367533 & 2015111 & 2807693 & 3235.4 & 2792.2 & 3730.8 \\
\hline 2015 & 1245178 & 1010487 & 1505040 & 1401.0 & 1147.7 & 1658.7 \\
\hline 2016 & 1145962 & 941150 & 1419792 & 1253.8 & 1041.5 & 1510.5 \\
\hline
\end{tabular}

\section{DISCUSSION}

Ethiopia showed remarkable progress in reducing the burden and reversing epidemic of HIV/AIDS in the last two decades. The country reduced the incidence of HIV/AIDS by $77 \%$, which surpasses the MDG target of 50\% incidence reduction (2).

Other reports of the United Nations (UN) also show that Ethiopia has achieved most of the MDG targets related to HIV $(19,20)$. However, there were very few studies that evaluated the burden of HIV/AIDS in Ethiopia. Hladik and colleagues reported that the prevalence of HIV/AIDS in Ethiopia was below 2\% in 1990 and reached $4.4 \%$ in 2003 and remained stable until 2008 (21). In the same study, the incidence rate of HIV/AIDS was $0.5 \%$ and $3.3 \%$ in rural and urban areas respectively in 1990. The modeled adult HIV incidence by the same authors for whole Ethiopia showed a steady but slow growth to $0.68 \%$ in 2003 and stabilized for the years 2004 $08(21)$.

This study using GBD data reveals that prevalence reaches its peak $(2 \%)$ in 2000 and declines to $1 \%$ in 2010 and remained stable since then. In addition, our study shows that the incidence rate steadily increaseed until $1995(0.3 \%)$ and dramatically declined to $0.04 \%$ in 2005 and remained stable. The prevalence and incidence rates in the GBD estimates are lower than the estimates made by Hladik et al. (21).

Our estimates of the number of AIDS deaths $(n=20,000)$ and number of people living with HIV $(n=670,906)$ in 2016 were different from the estimates of Ethiopian Public Health Institute (EPHI) and UNAIDS report $(5,22)$. Although the EPHI mortality estimate in $2016(n=19,743)$ is nearly the same as our estimate, GBD underestimates the number of people living with HIV compared to the EPHI estimate in the same year $(n=718,500)$. On the other hand, the prevalence of HIV/AIDS in $2015(1.21 \%)$ and $2016(1.18 \%)$ estimated by the Ethiopian Public Health Institute (EPHI) is similar to the GBD estimate (22).The differences in GBD estimates and other methods that use EPP could be due to the methodological differences. GBD has modified the EPP and the Spectrum in several ways as discussed in the previous sections and described in detail elsewhere (12).

The performance of Ethiopia in reducing the burden of HIV/AIDS and reversing this epidemic was remarkable particularly since 2000 (12). Several factors could have helped Ethiopia to achieve the MDG targets. The strong government leadership and political commitment in designing and implementing primary healthcare driven health services could have helped the country to achieve most of the MDG targets (23). Ethiopia

DOI: http://dx.doi.org/10.4314/ejhs.v29i1.7 
has also implemented an innovative communitybased health service delivery called Health Extension Program (HEP) since 2003 (23). Salaried and trained female Health Extension Workers (HEW) are involved in the HEP to give basic health package within the community. The HEW uses family folder at Kebele (lowest administrative unit) level to monitor the health service delivery and health status of the population. The HEP and the Family Folder have been instrumental to make health services accessible to the poor $(20,23-25)$. The HEP could be one of the contributors of an improved annual rate of change for the mortality rates of HIV/AIDS (11\%) between 2003 and 2015 (26).

The expansion of antiretroviral treatment (ART) free of charge since 2003 could be instrumental to reduce the incidence and mortality rates of HIV/AIDS (27). As a result of government commitment and direction, ART delivery has been scaled down to the primary healthcare unit to ensure better coverage and utilization for the poor (28). Some studies show that mortality decline among individuals living with HIV/AIDS in Ethiopia is consistent with ART coverage and uptake $(29,30)$. However, the ART coverage in adults (59\%) and children $(23 \%)$ is still very low in Ethiopia, which leads vulnerable populations to premature mortality $(5,31)$. The contribution of development partners to fight HIV/AIDS and TB (PEPFAR) has been also vital in fighting HIV/AIDS and TB in Ethiopia. The government has used flexible modalities of One-plan, One-budget and OneReport concept and effectively utilized the funding to scale up interventions towards HIV/AIDS and TB(32). Donors' funding could decline during the coming years, and Ethiopia should strengthen the low-cost and high impact HEP-based interventions to sustain progress $(11,33)$.

Despite considerable progress in the past, Ethiopia has now several challenges in achieving the 90-90-90 global targets of HIV/AIDS by $2020(5)$. Based on these global targets, $90 \%$ of the population should know their HIV status. Similarly, $90 \%$ of those who know their HIV should be treated and $90 \%$ of the treated should be virally suppressed by 2020 (5). There are several barriers for Ethiopia to achieve these targets in the coming years. TB/HIV co-infection and its impact on stigma and mental health problems could also be a big hurdle for the HIV/AIDS control program $(34,35)$. In the rural part of the country, stigma and prejudices are still widespread which needs tailored intervention (36). Continuous community mobilization, stigma reduction and care and support services have been vital for increasing utilization of ART services and improving retention in care that helps to reduce early mortality due to HIV/AIDS in Ethiopia (27). On the other hand, the level of funding for HIV/AIDS has declined recently that may affect the momentum of HIV interventions in Ethiopia.

This study is based on the GBD 2016 that uses comprehensive data sources and rigorous analysis. However, the study has some limitations. First, the use of verbal autopsy (VA) data in morality estimation may introduce misclassification bias. Use of published articles could introduce publication bias since unfavorable findings may not be published.

In conclusion, Ethiopia has achieved most of the MDG targets related to HIV/AIDS. However, the decline in HIV/AIDS mortality rate has been slow. Ethiopia should strengthen HIV case detection and treatment programs at community level through the HEP to reduce the burden of these diseases during the SDG-era.

\section{ACKNOWLEDGMENTS}

We are grateful to the team at the Institute of Health Metrics and Evaluation (IHME) at the University of Washington who allowed the Ethiopian National Burden of Diseases team (ENBD), to collaborate with the IHME, and use the GBD data to generate national estimates for Ethiopia. KD was funded by a Wellcome Trust Intermediate Fellowship in Public Health and Tropical Medicine [grant number 201900].

DOI: http://dx.doi.org/10.4314/ejhs.v29i1.7 


\section{REFERENCES}

1. WHO. From MDG To SDG. World Health Organization(WHO).

(Http://Apps.Who.Int/Iris/Bitstream/10665/20 0009/1/9789241565110_Eng.Pdf?Ua=1).Acc essed On November 28, 2017. 2015.

2. UN. The Millennium Development Goals Report. United Nations, 2015.

3. WHO. HIV/AIDS. Fact Sheet, World Health Organization(WHO).

(Http://Www.Who.Int/Mediacentre/Factsheet s/Fs360/En/2016). Accessed on August 24, 2018

4. FMOH. HIV Epidemic Estimates By Regional States And Ethiopia.FMOH(Federal Ministry Of Health), HIV/AIDS Prevention And Control Office 2015.

5. UNAIDS. Ending AIDS: Progress Towards The 90-90-90 Targets. UNAIDS, 2016.

6. 6. Federal Ministry Of Health. AIDS In Ethiopia, Sixth Report. MOH,Addis Ababa, 2016

7. GBD. Global, Regional, National, And Selected Subnational Levels Of Stillbirths, Neonatal, Infant, And Under-5 Mortality, 1980-2015: A Systematic Analysis For The Global Burden Of Disease Study(GBD) 2015. Lancet. 2016;388(10053):1725-74.

8. GBD. Global, Regional, And National Life Expectancy, All-Cause Mortality, And CauseSpecific Mortality For 249 Causes Of Death, 1980-2015: A Systematic Analysis For The Global Burden Of Disease(GBD) Study 2015. Lancet. 2016;388(10053):1459-544.

9. Liu L, Oza S, Hogan D, Chu Y, Perin J, Zhu J, Et Al. Global, Regional, And National Causes Of Under-5 Mortality In 2000-15: An Updated Systematic Analysis With Implications For The Sustainable Development Goals. Lancet. 2016;388(10063):3027-35.

10. Wang H, Wolock TM, Carter A, Nguyen G, Kyu HH, Gakidou E, Et Al. Estimates Of Global, Regional, And National Incidence, Prevalence, And Mortality Of HIV, 1980-
2015: The Global Burden Of Disease Study 2015. The Lancet HIV. 2016;3(8):E361-87.

11. FMOH. Health Sector Transformation Plan 2015/16 - 2019/20. MOH, Addis Ababa, 2015.

12. Murray CJ, Ortblad KF, Guinovart C, Lim SS, Wolock TM, Roberts DA, Et Al. Global, Regional, And National Incidence And Mortality For HIV, Tuberculosis, And Malaria During 1990-2013: A Systematic Analysis For The Global Burden Of Disease Study 2013. Lancet. 2014;384(9947):100570.

13. GBD. Global, Regional, And National Life Expectancy, All-Cause Mortality, And CauseSpecific Mortality For 249 Causes Of Death, 1980-2015: A Systematic Analysis For The Global Burden Of Disease Study 2015. Lancet. 2016;388(10053):1459-544.

14. Mortality GBD, Causes Of Death C. Global, Regional, And National Life Expectancy, AllCause Mortality, And Cause-Specific Mortality For 249 Causes Of Death, 19802015: A Systematic Analysis For The Global Burden Of Disease Study 2015. Lancet. 2016;388(10053):1459-544.

15. Collaborators GH. Estimates Of Global, Regional, And National Incidence, Prevalence, And Mortality Of HIV, 19802015: The Global Burden Of Disease Study 2015. The Lancet HIV. 2016;3(8):E361-E87.

16. Foreman KJ, Lozano R, Lopez AD, Murray CJ. Modeling Causes Of Death: An Integrated Approach Using Codem. Popul Health Metr. 2012;10:1.

17. Lozano R, Naghavi M, Foreman K, Lim S, Shibuya K, Aboyans V, Et Al. Global And Regional Mortality From 235 Causes Of Death For 20 Age Groups In 1990 And 2010: A Systematic Analysis For The Global Burden Of Disease Study 2010. Lancet. 2012;380(9859):2095-128.

18. Murray CJ, Ezzati M, Flaxman AD, Lim S, Lozano R, Michaud C, Et Al. GBD 2010: Design, Definitions, And Metrics. Lancet. 2012;380(9859):2063-6.

DOI: http://dx.doi.org/10.4314/ejhs.v29i1.7 
19. United Nations. Millennium Development Goals Report 2014. Assessment Of Ethiopia's Progress Towards The Mdgs. National Planning Commission(NPC) And The United Nations(UN) In Ethiopia. United Nations, 2015

20. Accorsi S, Bilal NK, Farese P, Racalbuto V. Countdown To 2015: Comparing Progress Towards The Achievement Of The Health Millennium Development Goals In Ethiopia And Other Sub-Saharan African Countries. Transactions of The Royal Society Of Tropical Medicine And Hygiene. 2010;104(5):336-42.

21. Hladik W, Shabbir I, Jelaludin A, Woldu A, Tsehaynesh M, Tadesse W. HIV/AIDS In Ethiopia: Where Is The Epidemic Heading? Sexually Transmitted Infections. 2006;82 Suppl 1:I32-5.

22. EPHI. HIV Related Estimates And Projections For Ethiopia. Ethiopian Public Health Institute(EPHI), Addis Ababa 2017.

23. Wakabi W. Extension Workers Drive Ethiopia's Primary Health Care. Lancet. 2008;372(9642):880.

24. Yassin MA, Datiko DG, Tulloch O, Markos $\mathrm{P}$, Aschalew M, Shargie EB, Et Al. Innovative Community-Based Approaches Doubled Tuberculosis Case Notification And Improve Treatment Outcome In Southern Ethiopia. Plos One. 2013;8(5):E63174.

25. Gebrehiwot TG, San Sebastian M, Edin K, Goicolea I. The Health Extension Program And Its Association With Change In Utilization Of Selected Maternal Health Services In Tigray Region, Ethiopia: A Segmented Linear Regression Analysis. PlosOne. 2015;10(7):E0131195.

26. GBD. Millennium Development Goals(MDG) Visualization. The Global Burden Of Disease Study ( Https://Vizhub.Healthdata.Org/Mdg/. 2017). accessed on August 24, 2018.
27. Assefa Y, Alebachew A, Lera M, Lynen L, Wouters E, Van Damme W. Scaling Up Antiretroviral Treatment And Improving Patient Retention In Care: Lessons From Ethiopia, 2005-2013. Globalization And Health. 2014;10:43.

28. Assefa Y, Kloos H. The Public Health Approach To Antiretroviral Treatment (ART) Service Scale-Up In Ethiopia: The First Two Years Of Free ART, 2005-2007. Ethiopian Medical Journal. 2008;46(4):401-6.

29. Reniers G, Araya T, Davey G, Nagelkerke N, Berhane Y, Coutinho R, Et Al. Steep Declines In Population-Level AIDS Mortality Following The Introduction Of Antiretroviral Therapy In Addis Ababa, Ethiopia. AIDS. 2009;23(4):511-8.

30. Floyd S, Marston M, Baisley K, Wringe A, Herbst K, Chihana M, Et Al. The Effect Of Antiretroviral Therapy Provision On AllCause, AIDS And Non-AIDS Mortality At The Population Level--A Comparative Analysis Of Data From Four Settings In Southern And East Africa. Trop Med Int Health. 2012;17(8):E84-93.

31. WHO. Update Ethiopia HIV/AIDS Progress In 2014, World Health Organization(WHO). (Http://Www.Afro.Who.Int/En/Ethiopia/Coun try-Programmes/Topics/4480-Hivaids.Html). Accessed on august 24, 2018.

32. Waddington C, Alebachew A, Chabot J. Roadmap For Enhancing The Implementation Of One Plan, One Budget And One Report In Ethiopia. MOH, Addis Ababa, 2012.

33. Teklehaimanot HD, Teklehaimanot A. Human Resource Development For A Community-Based Health Extension Program: A Case Study From Ethiopia. Human Resources For Health. 2013;11:39. 
34. Deribew A, Hailemichael Y, Tesfaye M, Desalegn D, Wogi A, Daba S. The Synergy Between TB And HIV Co-Infection On Perceived Stigma In Ethiopia. BMC Research Notes. 2010;3:249.

35. Deribew A, Negussu N, Kassahun W, Apers L, Colebunders R. Uptake Of ProviderInitiated Counselling And Testing Among Tuberculosis Suspects, Ethiopia. The
International Journal Of Tuberculosis And Lung Disease. 2010;14(11):1442-6.

36. Deribew A, Abebe G, Apers L, Jira C, Tesfaye M, Shifa J, Et Al. Prejudice And Misconceptions About Tuberculosis And HIV In Rural And Urban Communities In Ethiopia: A Challenge For The TB/HIV Control Program. BMC Public Health. 2010;10:400. 